\title{
Successful Resection of a Non-functional Paraganglioma with Celiac Trunk Invasion Followed by Common Hepatic Artery Reimplantation - A Case Report and Literature Review
}

\author{
NICOLAE BACALBASA ${ }^{1 *}$, IRINA BALESCU $^{2}$, ALINA TANASE $^{3 *}$, IULIAN BREZEAN $^{1,4 *}$, \\ MIHAELA VILCU ${ }^{1,4 *}$ and VLADISLAV BRASOVEANU ${ }^{5}$ \\ 1 "Carol Davila” University of Medicine and Pharmacy, \\ Center of Excellence in Translational Medicine - Fundeni Clinical Institute, Bucharest, Romania; \\ 2 "Ponderas" Academic Hospital, Bucharest, Romania; \\ ${ }^{3}$ Department of Stem Cell Transplantation, Fundeni Clinical Institute, Bucharest, Romania; \\ 4 “I. Cantacuzino" Clinical Hospital, Bucharest, Romania; \\ 5 "Dan Setlacec” Center of Gastrointestinal Disease and Liver Transplantation, \\ Fundeni Clinical Institute, Bucharest, Romania
}

\begin{abstract}
Paragangliomas, as well as phaeochromocytomas, are vascular neuroendocrine lesions that might be encountered between neck and pelvis. In certain cases, a preoperative diagnosis is difficult to be established, so resection might be needed whenever a suspect mass is discovered at the imaging studies. Moreover, there are cases in which resection and reconstruction of an important vascular structure might be imposed. In this case report a 59. year-old patient was investigated for upper abdominal pain with postprandial features and was diagnosed with a retroperitoneal tumor of $4 / 6 / 7 \mathrm{~cm}$ invading the celiac trunk. The tumor was successfully resected and the common hepatic artery was reinserted in the celiac stump.
\end{abstract}

Paragangliomas are well vascularized tumors with a sympathetic or parasympathetic origin that might develop in any location between the skull base and pelvis with an estimated rare of malignancy of $17 \%(1,2)$. They usually arise from specialized neural crest cells, which are usually encountered in the medullary part of the adrenal glands; however, in up to $10 \%$ of cases an extra-adrenal location is reported, the most common sites being the para-aortic and

This article is freely accessible online.

*The Authors contributed equally to this study.

Correspondence to: Irina Balescu, "Ponderas" Academic Hospital, Bucharest, Romania. Tel: +40 724077709, e-mail: irina.balescu@ ponderas-ah.ro

Key Words: Retroperitoneal tumor, paraganglioma, celiac trunk resection, hepatic artery reinsertion. peri-nephric spaces (3-5). Extra-adrenal lesions usually arise from the parasympathetic paraganglia and are usually located in the aortic bifurcation (6).

In certain cases, invasion of the surrounding vascular structures might be encountered; in such cases the therapeutic strategy may consist of surgery versus radionuclide therapy and chemotherapy, the decision being taken after a careful analysis of the case and after discussing the decision with the patient (7).

\section{Case Report}

A 59-year-old male was investigated for postprandial upper abdominal pain and was diagnosed with a retroperitoneal tumor measuring 4/6/7 $\mathrm{cm}$ using magnetic resonance imaging; the tumor was located posteriorly to the pancreatic head and the spleno-mesenteric confluent. The preoperative workup was completed by performing an upper and a lower digestive endoscopy; however, no other pathological finding was revealed. The patient was submitted to surgery, a retroduodenopancreatic tumor invading the celiac trunk being revealed, so the tumor was resected en bloc with the celiac axis (Figure 1). The common hepatic artery was reinserted in the celiac stump at the level of the abdominal aorta (Figure 2). The postoperative course was uneventful, and the patient was discharged in the fifth postoperative day. The abdominal ultrasound performed at discharge confirmed the functionality of the vascular reconstruction, the resistive index of the hepatic artery being de 0.64; in the meantime, there was no sign of free intraperitoneal fluid (Figure 3 ). The histopathological studies revealed the presence of a paraganglioma; none of the 23 resected lymph nodes (from the origin of the common hepatic artery and from the origin of the celiac trunk) presented any tumor infiltration. 


\section{Discussion}

Paragangliomas are rare tumors classified as functional or non-functional lesions. When functional, these lesions will induce catecholamine hypersecretion, the main related symptoms being related to this hormonal excess; in such cases the most common symptoms consist of headache, visual disturbances or palpitations (8). In cases with nonfunctional lesions, symptoms are rather related to the mass syndrome or even to the invasion of the surrounding viscera or blood vessels; the non-functional paragangliomas account for up to $15 \%$ of cases (9). In isolated cases, patients with non-functional intra-abdominal paragangliomas might have paralytic ileus or chest pain (10-11). Due to the low specificity of these symptoms, non-functional lesions are usually difficult to be diagnosed pre-operatively (12).

For example, in our case, symptoms were most likely related to the invasion of the celiac axis, inducing a significant reduction of blood flow in the emergent arteries. In such cases complex surgery involving vascular resections might be needed in order to achieve a good local control of the disease. However, it should not be omitted the fact that a multidisciplinary approach is mandatory (1). Due to the malignant potential of such tumors, surgery should be taken in consideration even in cases located in the close proximity of vital blood vessels (12).

When it comes to the intraoperative strategy, the reconstruction manner depends on the extent and location of the invasion area. In patients presenting extended vascular invasion, prosthetic materials such as Gore-Tex or polytetrafluoroethylene might be needed, while in cases presenting a lower grade of invasion direct reimplantation might be tempted $(13,14)$. However, once the surgical techniques of abdominal visceral resections en bloc with vascular resections and reconstructions improved, this type of surgery has gained more popularity and has been successfully implemented as part of the therapeutic strategy of various tumor subtypes (15-17).

An interesting case series of five patients diagnosed with paragangliomas or phaeochromocytomas invading the greater vessels in which resection was successfully performed comes from Srirangalingam and co., in 2017 (1). Among these cases, aorta was involved in four cases (three patients presenting thoracic arc of the aorta invasion while the fourth case was diagnosed with an abdominal paraganglioma invading the abdominal aorta) while inferior cava vein was involved in one case (via the adrenal vein in a patient diagnosed with a phaeochromocytoma). In all cases the tumors were resected en bloc with the vascular segment which had been invaded, the vascular continuity being reestablished by aorta transection and cardiopulmonary bypass (in three cases presenting intrathoracic lesions), aorta resection and Dacron graft (in the case presenting abdominal aorta invasion due to an abdominal paraganglioma) and respectively by inferior vena cava patch wall resection en bloc with nephrectomy and adrenalectomy in one case; however in this case remnant tumoral tissue was seen in the adrenal bed. The postoperative course was uneventful in all cases; when it comes to the long-term outcomes, all the four cases in which a complete resection was achieved no recurrent lesions were encountered after a follow-up period ranging between one and eight years (1).

In cases in which surgery is not feasible (unresectable lesions, poor biological condition of the patient) radiotherapy, chemotherapy, embolization or even radionuclide therapy might be attempted in order to reduce the tumor size and to control the symptoms (18-20). However, a therapeutic strategy should be performed whenever the diagnosis of paraganglioma is suspected due to the fact that up to $42 \%$ of cases might metastasize, the most common sites of metastatic disease consisting of liver, lymph nodes, bones and lungs (12); moreover, once metastatic disease occurs, the chances of long term survival significantly decreases, only one third of such patients being alive at the five-year follow-up (21).

An interesting case in which embolization followed by resection as a second stage procedure was successfully performed comes from Martinez et al. and published in 2012 (22). The authors reported the case of a 24-year-old man who presented for acute left quadrant abdominal pain in whom an internal hernia or volvulus was suspected during the preoperative studies. In consequence, the patient was submitted to emergency surgery; intraoperatively the diagnosis of internal hernia was confirmed. However, once the laparotomy was performed, an incidental subdiaphragmatic tumor with diaphragmatic invasion was revealed; although at manipulation there was no modification of the blood pressure, the tumor seemed to have an important pulsatile activity so at the moment no surgical action was performed. At six days postoperatively the patient was submitted to an angiography which revealed the presence of a branch of the right renal artery assuring the blood supply of the tumor; therefore a percutaneous embolization was performed, followed by successful resection of the tumor en bloc with the invaded areas of the diaphragm and of the pericardium two days later. The histopathological analysis of the tumor demonstrated the presence of a paraganglioma, with negative resection margins (22).

\section{Conclusion}

Paragangliomas are rare neuroendocrine tumors with a sympathetic or parasympathetic origin that might develop in the close proximity of the vital intra-abdominal vascular structures. Unfortunately, especially in patients with nonfunctional lesions a preoperative diagnosis is hard to establish. However, in any case in which a paraganglioma 


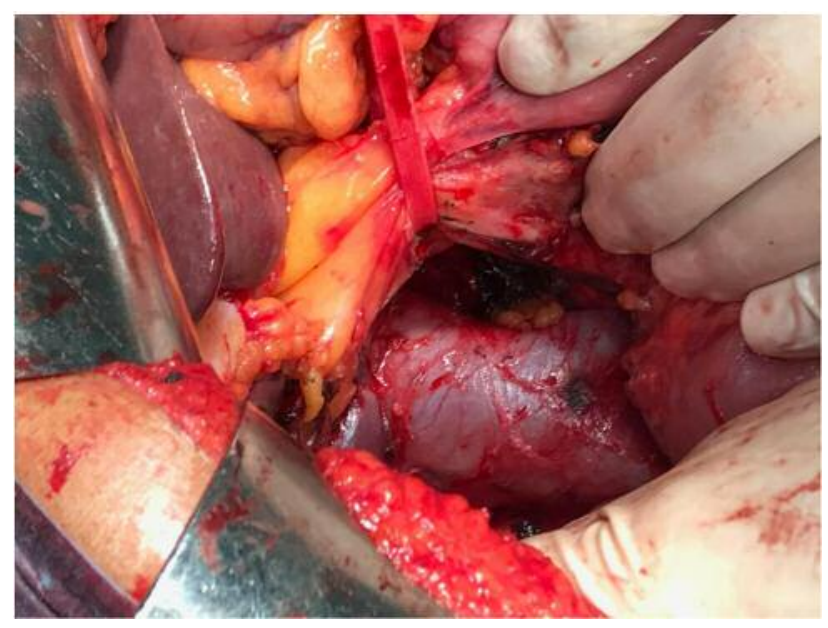

Figure 1. The final aspect after resecting the tumor en bloc with the celiac axis.

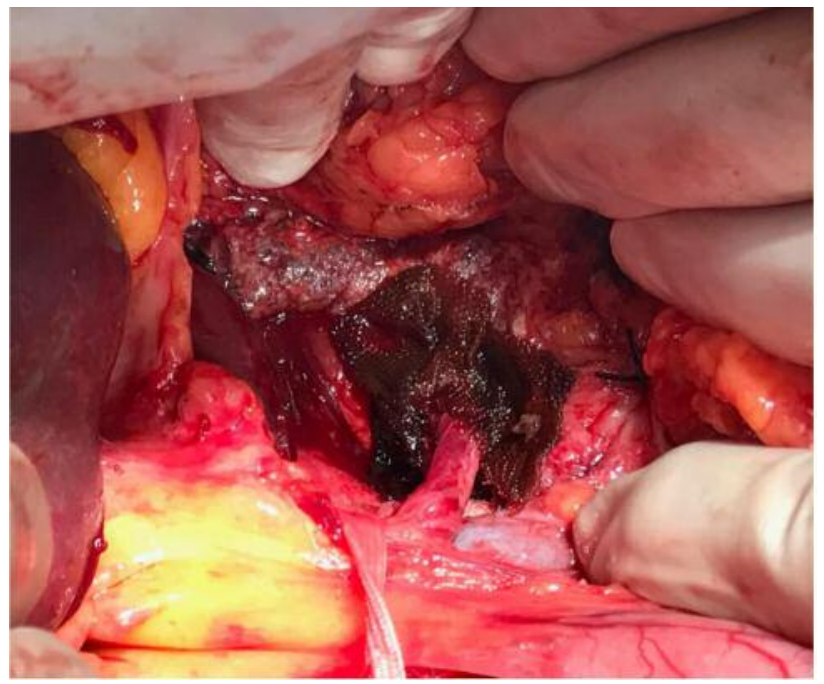

Figure 2. The final aspect after reimplantation of the common hepatic artery in the abdominal aorta.

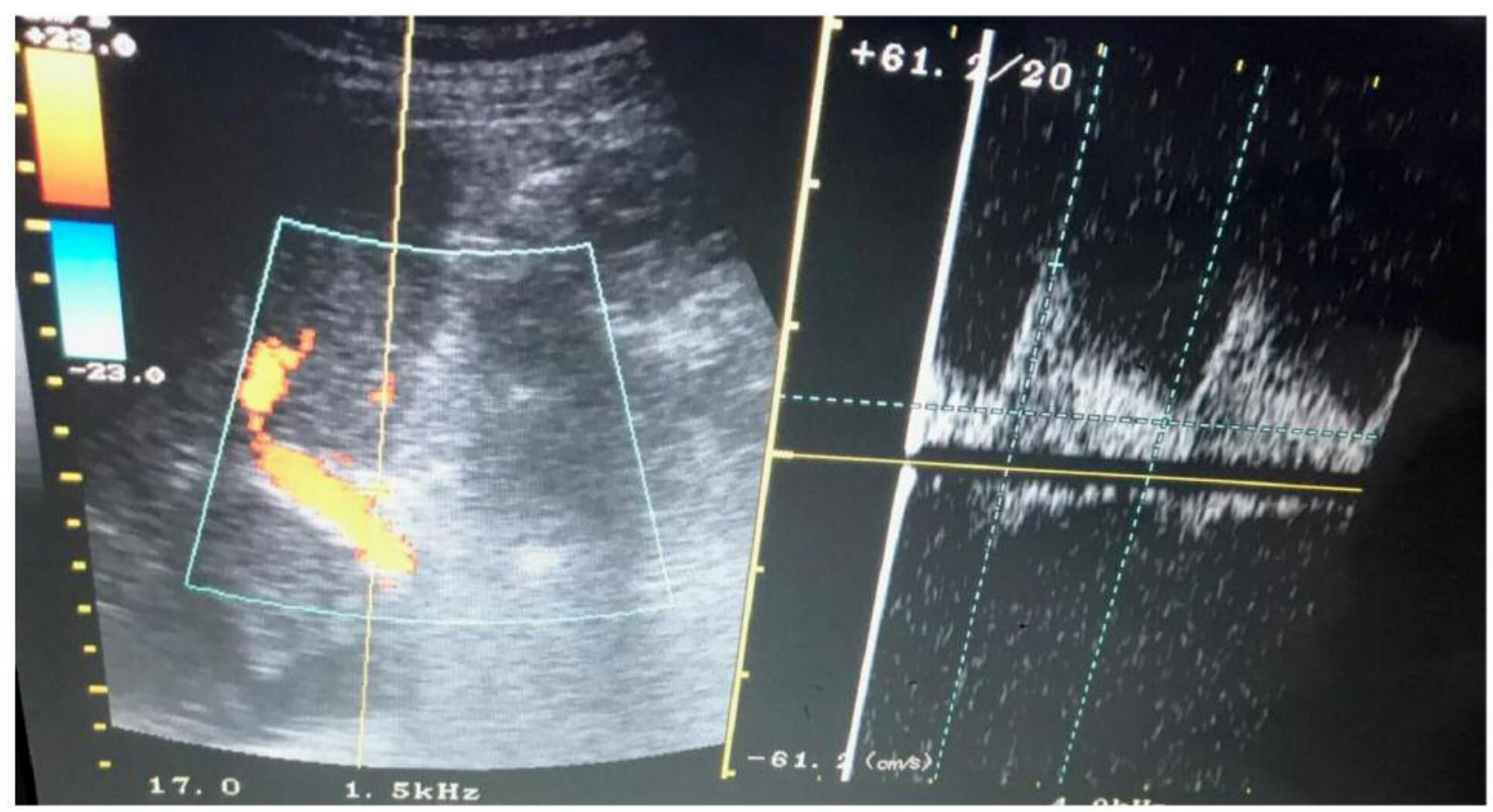

Figure 3. Doppler ultrasound demonstrating a proper blood flow at the level of the common hepatic artery.

is suspected, surgery should be taken into consideration in order to entirely remove the lesion and to provide a good local control of the disease. In certain cases, major vascular resections might be needed; in such cases vascular reconstruction by direct re-implantation or by using a prosthetic material should be performed. Due to the recent improvement of the surgical techniques, vascular resection and re-implantation has gained popularity and the procedure is more often performed in the last decades with good outcomes. 


\section{References}

1 Srirangalingam U, Gunganah K, Carpenter R, Bhattacharya S, Edmondson SJ and Drake WM: Phaeochromocytoma and paraganglioma excision involving the great vessels. EJVES Short Rep 35: 1-6, 2017.

2 Ayala-Ramirez M, Feng L, Johnson MM, Ejaz S, Habra MA, Rich T, Busaidy N, Cote GJ, Perrier N, Phan A, Patel S, Waguespack S and Jimenez C: Clinical risk factors for malignancy and overall survival in patients with pheochromocytomas and sympathetic paragangliomas: primary tumor size and primary tumor location as prognostic indicators. J Clin Endocrinol Metab 96: 717-725, 2011.

3 Feng N, Zhang WY and Wu XT: Clinicopathological analysis of paraganglioma with literature review. World J Gastroenterol 15: 3003-3008, 2009.

4 Wen J, Li HZ, Ji ZG, Mao QZ, Shi BB and Yan WG: A case of large "silent" extra-adrenal retroperitoneal paraganglioma resected laparoscopically. Chin Med Sci J 25: 61-64, 2010.

5 Whalen RK, Althausen AF and Daniels GH: Extra-adrenal pheochromocytoma. J Urol 147: 1-10, 1992.

6 DeLellis RA, Lloyd RV, Heitz PU and Eng C: Pathology and genetics of tumours of endocrine organs. In: World Health Organization Classification of Tumours, IARC Press, Lyon, France, 2004.

7 Jimenez C, Rohren E, Habra MA, Rich T, Jimenez P, AyalaRamirez $M$ and Baudin E: Current and future treatments for malignant pheochromocytoma and sympathetic paraganglioma. Curr Oncol Rep 15: 356-371, 2013.

8 Beilan JA, Lawton A, Hajdenberg $\mathrm{J}$ and Rosser CJ: Pheochromocytoma of the urinary bladder: a systematic review of the contemporary literature. BMC Urol 13: 22, 2013.

9 Adraktas D, Caserta M and Tchelepi H: Paraganglioma of the urinary bladder. Ultrasound Q 30: 233-235, 2014.

10 Brahmbhatt P, Patel P, Saleem A, Narayan R and Young M: Retroperitoneal paraganglioma presenting as a chest pain: a case report. Case Rep Oncol Med 2013: 329472, 2013.

11 Lin WC, Wang HY, Chang CW, Lin JL and Tsai CH: Retroperitoneal paraganglioma manifesting as paralytic ileus: a case report. J Med Case Rep 6: 158, 2012.

12 Gannan E, van Veenendaal P, Scarlett $\mathrm{A}$ and $\mathrm{Ng} \mathrm{M}$ : Retroperitoneal non-functioning paraganglioma: A difficult tumour to diagnose and treat. Int J Surg Case Rep 17: 133-135, 2015.
13 Srirangalingam U, Walker L, Khoo B, MacDonald F, Gardner D, Wilkin TJ, Skelly RH, George E, Spooner D, Monson JP, Grossman AB, Akker SA, Pollard PJ, Plowman N, Avril N, Berney DM, Burrin JM, Reznek RH, Kumar VK, Maher ER and Chew SL: Clinical manifestations of familial paraganglioma and phaeochromocytomas in succinate dehydrogenase B (SDH-B) gene mutation carriers. Clin Endocrinol (Oxf) 69: 587-596, 2008.

14 Bamous M, Henaine R, Wautot F, Ngola J, Lantelme P and Ninet $\mathrm{J}$ : Resection of secreting cardiac pheochromocytoma with and without cardiopulmonary bypass. Ann Thorac Surg 90: e1-e3, 2010.

15 Brasoveanu V, Anghel C, Barbu I, Pautov M, Ionescu MI, Motthor M, Balescu I, Dima S and Bacalbasa N: Pancreatoduodenectomy en bloc with portal and superior mesenteric artery resection - a case report and literature review. Anticancer Res 35: 1613-1618, 2015.

16 Bacalbasa N, Brezean I, Anghel C, Barbu I, Pautov M, Balescu I and Brasoveanu $\mathrm{V}$ : Management of a fulminant upper gastrointestinal bleeding exteriorized through hemobilia due to arteriobiliary fistula between the common bile duct and a right hepatic artery aneurysm - A case report. In Vivo 31: 983-989, 2017.

17 Bacalbasa N, Brezean I, Anghel C, Barbu I, Pautov M, Balescu I and Brasoveanu V: Successful resection and vascular ligation of a large hepatic artery aneurysm - A case report and literature review. In Vivo 31: 979-982, 2017.

18 Bryant RL, Stevenson DR, Hunton DW, Westbrook KC and Casali RE: Primary malignant retroperitoneal tumors. Current management. Am J Surg 144: 646-649, 1982.

19 Mikhail RA, Moore JB, Reed DN Jr. and Abbott RR: Malignant retroperitoneal paragangliomas. J Surg Oncol 32: 32-36, 1986.

20 Pantea S, Jiga L, Ionac M and Lazar F: Arterio-venous fistula using nonpenetrating titanium clips (VCS). Chirurgia (Bucur) 108: 563-567, 2013

21 Sclafani LM, Woodruff JM and Brennan MF: Extraadrenal retroperitoneal paragangliomas: natural history and response to treatment. Surgery 108: 1124-1129, 1990.

22 Martinez JD, Zendejas B, Luna JP, Lopez J, Luna SS, MendozaSanchez F and Farley DR: Left subdiaphragmatic paraganglioma supplied by contralateral right renal artery. Int J Surg Case Rep 3: 333-337, 2012.

Received February 27, 2018

Revised March 22, 2018

Accepted March 23, 2018 